INFORMÁTICA NA EDUCAÇ̃̃O:

teoria \& prática Porto Alegre, v.10, n.2, jul./dez. 2007. ISSN $1516084 X$

\title{
Verdades lógico-matemáticas no limite do esvaziamento [do] estético
}

Alessandro Zir

\section{Logico-mathematical truths at the limits of aesthetic exhaustion}


Resumo: A discussão aqui proposta parte de uma crítica feita por Howard Delong, ainda na década de 70, ao existencialismo, filosofia que há muito saiu de moda. $O$ resgate dessa crítica revela-se, no entanto, pertinente para o momento presente, porque posições filosóficas importantes e em voga na atualidade correm o risco de esvaziamento similar. Considerações epistemológicas mais gerais avançadas por Delong e outros autores com base em resultados obtidos nos âmbitos mais restritos da lógica, da matemática e da teoria da computação permanecem um antídoto válido contra tal esvaziamento. Tais considerações permitem um ultrapassar da trivialidade de posições meramente céticas e historicistas, evitando o puro e simples abandono de noções mais substanciais como verdade ou intuição. Conclui-se com a defesa de que um resgate dessas últimas noções faz-se necessário inclusive no âmbito de áreas não estritamente científicas, como a crítica literária.

Palavras-chave: Critica. Filosofia. Literatura. Verdade. Teoremas limitativos.

Abstract: The discussion proposed here starts from a criticism presented by Howard Delong, still in the 70's, against existentialism, a philosophy long ago out of fashion. The recovery of this criticism turns out to be legitimate to the present moment, because important philosophical positions that are popular nowadays run the risk of a similar exhaustion. General epistemological views advanced by Delong and other authors concerned with results obtained in the more circumscribed fields of logic, mathematics and computation theory, remain a valid antidote to such an exhaustion. These views enable one to transcends the triviality of merely skeptical and historicist positions, avoiding a simple neglect of substantial notions such as truth and intuition. The discussion concludes by defending that it is necessary to rescue these last notions even in non-scientific fields such as literary criticism.

Keywords: Literary criticism. Literature. Philosophy. Truth. Limitative theorems.

ZIR, Alessandro. Verdades lógico-matemáticas no limite do esvaziamento (do) estético. Informática na Educação: teoria \& prática, Porto Alegre, v.10, n. 2, p.67-76, jul./dez. 2007. 
Num livro clássico que fornece um excelente apanhado dos principais desenvolvimentos em lógica matemática do início do século $\mathrm{XX}$, Howard Delong afirma o seguinte:

Até onde sei, nem mesmo um dos existencialistas de destaque - Heidegger, Sartre, Jaspers, Merleau-Ponty sequer mencionou os teoremas limitativos [da metamatemática]. Os existencialistas discordam entre si a respeito de varias coisas, mas eles iriam concordar em não conceder grande importância e muito menos uma importância central —, em sua teoria do conhecimento, a uma matéria técnica como a lógica matemática. E no entanto eles pretendem falar de prova, ou de verdade, ou das limitações do homem. (1970, p. 228) ${ }^{1}$.

O livro de Delong permanece sendo publicado até hoje, e tem sido reconhecido por fornecer uma análise lúcida das implicações filosóficas dos chamados teoremas limitativos da metamatemática. Nesse sentido, Delong é referido e elogiado como um antecessor por Douglas Hofstadter, no seu Gödel, Escher and Bach (1979, p. 747), livro que alcançou bem mais ampla repercussão, ganhando inclusive um premio Pulitzer. Tanto Hofstadter quanto Delong abordam um conjunto de questões similares que dizem respeito, em ultima instância, a implicações mais amplas dos referidos teoremas limitativos, para além do âmbito restrito da lógica matemática e teoria da computação. As mesmas questões foram em seguida retomadas num outro livro de Hofstadter: Metamagical themas: questing for the essence of mind and pattern(1985).

Voltando à citação de Delong, o que está nela em jogo é uma reconsideração do existencialismo - filosofia cética em moda no período em que o livro era escrito - em vista dos teoremas limitativos. Ficam subentendidas certas implicações desses últimos no que se refere ao conhecimento humano e à noção de verda- de, as quais tinham já sido exploradas ao longo dos outros capítulos do livro. Essas implicações são as seguintes:

[...] o que conta como verdade em aritmética depende do que as pessoas decidem ser aritmeticamente verdadeiro... Assim como não pode haver uma explicação abstrata sistemática e completa de por que falamos inglês do jeito que falamos, também aqui não pode haver explicação completa de por que aceitamos uma ao invés de outra afirmação como aritmeticamente verdadeira. (DELONG, 1970, p. 225)².

Isso posto, o que Delong critica no existencialismo não é necessariamente sua postura cética, ou seu historicismo. Antes pelo contrário, o ponto criticado por Delong é o de que existencialistas falam sobre finitude e limite em completa ignorância de certas implicações da lógica matemática que dariam excelente aporte para a defesa de muitas de suas posições. Mais grave ainda, por causa desse desconhecimento, existencialistas geralmente tratam a lógica e a matemática como disciplinas irrelevantes ou mesmo nocivas no que interessa a um entendimento de suas posições.

Há duas questões aqui: por um lado:

a) háa questão da relevância de certos resultadosalcançados numâmbito tão técnicoerestrito como o da lógica matemática para outras áreas da cultura, como as ciências humanas, a filosofia eapsicologia, por exemplo.

Poroutrolado:

b) há a questão da visão geral equivocadaque se tem ou tinha da lógica eda matemáticaem áreas como a filosofia. Não há espaço aqui para se substancializar mais pormenorizadamente oque seria essa visão equivocada. No entanto, todos os que já tiveram contato com a filosofia acadêmica e outras disciplinas daschamadasciências humanas podem 
ter constatado que o discurso em geral dessas disciplinas no que se refere à lógica eà matemática oscila entre duas posturas dicotômicas: a postura conservadora que pressupõeserema matemáticaea lógica os arautos das noções tradicionais de objetividade everdade, e a postura iconoclasta que supostamentedesmascara a matemáticaea lógica como exemplos mais evidentes de fetichismo e hipostasiação do que seriam meras categorias contingentes do pensamento apresentadas de forma absoluta. É possível que a primeira questão seja mais bem respondida pela negativa. Talvez a matemáticaea lógica tenham realmente muito pouco a ensinar para disciplinas em outras áreas da cultura, e menos ainda para a filosofia ou as chamadas ciências humanas e sociais. Ainda assim, a crítica de Delong permanece válida pela segunda questão. Quer dizer, por demandar uma revisão de uma concepção duplaextremamente simplistae incorretaque se tem da lógica e da matemática - uma moeda conservadora/iconoclasta que se circula aqui e ali.

De fato, como mostra o livro de Delong, no início do século XX, pôde-se constatar de forma contundente a existência de limites intrínsecos ao conhecimento que afetam exatamente essas disciplinas, tidas como os arautos (legítimos ou embusteiros) da objetividade e da verdade, antes do que quaisquer outras. E foi em função mesmo do rigor da lógica e da matemática, tidas tradicionalmente como áreas das mais seguras, e dos métodos de formalização a elas associados, que tais resultados puderam ser obtidos. Daí surgem as constatações referidas noparágrafo anteriorquanto ao que pode contarcomo verdade em aritmética. A história começa mais ou menosem 1904, quando o matemático alemão David Hilbert sugere que a lógica simbólica pode ser trata- da como um ramo da teoria dos números. Quem no entanto operacionalizou uma correspondência entre as duas áreas foi o lógico e matemático austríaco Kurt Gödel. A partir desse resultado, Gödel foi capaz de investigar com uma clarezasem precedentescertas propriedades gerais de sistemas dedutivos formalizados, como consistência e completude (KNEALE; KNEALE, 1962, p. 714-715).

Em termos lógicos, um sistema é dito consistente se ele está livre de contradição. Do ponto de vista semântico, isso significa que há um modelo com que eu posso interpretar o sistema. Do ponto de vista sintático, isso significa que não há nenhuma fórmula $P$, tal que tanto $P$ quanto a negação $P$ possam ser provadas a partir dos axiomas e regras dedutivas do sistema. Completude significa, por sua vez, que qualquer proposição verdadeira capaz de ser expressa por uma fórmula do sistema pode ser provada a partir dos axiomas e regras dedutivas do sistema. Um sistema formal rico o suficiente para expressar a aritmética seria dito consistente se não implicasse em contradição no sentido indicado. Um sistema formal rico o suficiente para expressar a aritmética seria dito completo se permitisse provar qualquer proposição aritmética verdadeira. São essas as propriedades que Gödel vai investigar a partir da correspondência que ele estabelece entre lógica simbólica e teoria dos números.

A correspondência operacionalizada por Gödel significou, já em si mesma e antes de qualquer outro resultado, a descoberta de um isomorfismo inaudito entre números e expressões formais. Conforme coloca Hofstadter:

[...] é como se alguém tivesse conhecido partituras musicais por toda a vida, mas somente de forma visual - e então, subitamente, aprendesse de outra pessoa a relação existente entre os sons e as partituras musicais. Que riqueza, um novo mundo! (1979, p. 263) ${ }^{3}$. 
Emseguida, dentro desse universo de novas relações, através do uso de umargumento similar ao chamado argumento diagonal, utilizado por Georg Cantor na sua prova da não enumerabilidade dos reais, e de uma versão modificada da antinomia do mentiroso que remonta a Eubulides (séc. IV A. C.), Gödel é capaz de provar que qualquer sistema formal rico o suficiente para expressar a aritmética elementar ou éinconsistente ou incompleto (DAWSON, 1997, p. 65; cf. GÖDEL, 1995, p. 30-31, 292). Depois disso, Alonso Churche Alan Turing contribuíram com novos teoremas limitativos tendo conseqüênciastambémparaaáreadacomputação.

O uso do argumento diagonal na prova da não enumerabilidade dos reais (estabelecida originalmente por Cantor ainda no século XIX) pode ser explicado da seguinte maneira. Considerem-se os números reais entre 0 e 1 . Suponhase uma lista infinita em que fosse possível alinhar cada integral positivo natural com um desses números reais (não importando a ordem desses últimos):

$$
\begin{aligned}
& 1-0.12349876 \ldots \\
& 2-0.43987438 \ldots \\
& 3-0.09128374 \ldots \\
& 4-0.98374345 \ldots
\end{aligned}
$$

Agora, usam-se os números diagonais em negrito para construção de um número real entre 0 e 1 que não está na lista. Tomam-se esses números na ordem em que aparecem, depois do ponto decimal, e modificam-se cada um deles para algum outro número. Isso pode ser feito de inúmeras maneiras. Pode se propor uma regra simples, como a seguinte: altera-se cada número para3 sempre que no original ele for diferente de 3 , e quando ele for igual a 3 no original, é alterado para $0 . \mathrm{Na}$ lista aqui apresentada, seguindo-se a regra propos- ta, tería-se como resultado o seguinte número real: 0.3033... Tal número real evidentemente não estána lista original (infinita), pois ele necessariamente difere do primeiro número da lista no primeiro digito decimal, do segundo número da lista no segundo digito decimal, e assim por diante.

Com relação à antinomia do mentiroso, ela pode ser expressa de mais de uma maneira. Delong dá os seguintes três exemplos provavelmente conhecidos já dos gregos: "(1) Os cidadãos de Creta sempre mentem (proferido por um cidadão de Creta). (2) Quem quer que diga 'eu minto' mente e diz a verdade ao mesmo tempo. (3) Esta proposição não é verdadeira" (1970, p. 30). Tais formulações implicam numa contradição sempre que se tenta atribuir a elas um valor de verdade (falso ou verdadeiro), e é por isso que são ditas antinomias. Por causa do isomorfismo que ele descobre entre números e expressões formais, Gödel é capaz de se valer de um processo de diagonalização semelhante ao anteriormente explicado, mas em relação a sistemas formais ricos o suficiente para expressar a aritmética. Desse processo de diagonalização, Gödel obtém uma proposição indecidível num sentido similar ao da antinomia do mentiroso. A formulação no caso seria não "essa proposição não é verdadeira", mas "essa proposição não é provável". Esse resultado implica que sistemas formais ricos o suficiente para expressar a aritmética são ou inconsistentes ou incompletos. É daí que decorre a afirmação já referida de Delong de que "[...] não pode haver uma explicação abstrata sistemáticae completa... de porqueaceitamos umaao invés de outraafirmação como anitmeticamenteverdadeira"(1970, p.225).

Alan Turing chega a resultados semeIhantes aos de Gödel no que diz respeito à computação. Isso se segue à sua formulação do conceito de máquina de Turing, em termos do qual se pode definir de forma direta e persuasiva opera- 
ções matemáticas mecânicas tradicionalmente denominadas dealgorítmicas (PENROSE, 1989, p. 34, 47). Uma maquina de Turing seria qualquer máquina capaz de passar de um estado a outro atrés de um conjunto simples de regras de transição. Uma máquina de Turing universalseria, por sua vez, uma máquina de Turing capaz de operar de forma indistingüível aqualqueroutramáquina de Tuning, bastanto para isso que fosse alimentada com um número codificando a estrutura da máquina que se quer imitar. Uma máquina de Turing universal permitiria determinar previamente situações em que outras máquinas de Turing entrariam em loop, quer dizer, situações em que elas ficariam impossibilitadas de mudar de estado ao seguir certas regras para elas indecidíveis. No entanto, a possibilidade desse tipo de reconhecimento revela-se bastante limitada, pelo fato de que as próprias máquinas de Turing universais estão sujeitas a entrar em loop, particularmente nos casos em que são alimentadas com um número codificando sua própria estrutura (HOFSTADTER, 1985, p. 486).

O que foi dito até aqui, deve deixar entrever o suficiente o quanto a moeda corrente da lógica e da matemática como os arautos anteriormente referidos é ingênua e incorreta. Avança-se também a partir de agora para a questão mais problemática anteriormente aludida, a saber, a relevância de resultados alcançados no domínio da matemática e da lógica para outras áreas da cultura que tratam de temas diversos. Como já se afirmou, essa questão é extremamente controversa. Descartada a moeda corrente, por demais desgastada, nada impede, entretanto, que se imaginem outras de validade insuspeita que viabilizem algum tipo mais efetivo de troca. Elas podem ser usadas, inclusive, em mais de uma direção (não só da matemática à filosofia, mas da filosofia à matemática). Em sua reflexão sobre os desenvolvimentos em metamatemática que levaram aos resultados dos teoremas limitativos, Delong se vale mais uma vez da filosofia (mas agora não para fazer crítica), alinhando, de forma mais que curiosa, aqueles quesão considerados geralmente antíteses na história do pensamento ocidental: Platão e Nietzsche ${ }^{4}$. Conforme Delong (1970), tanto para um quanto para o outro desses filósofos, quando se tenta alcançar uma definição última do que seja a natureza da realidade, mesmo dentro de uma disciplina específica, não se obtém outra coisa senão mitos. Aqui Delong aponta para o fato de que para Platão um conhecimento das Formas não pode ser veiculado senão através de uma linguagem poética ealusiva. Em relação a Nietzsche, Delong aponta para o argumento de que na periferia de qualquer ciência, a própria lógica que a constitui freqüentemente se inverte de forma desconstrutiva (p. 226).

A idéia de que um conhecimento das Formas - quer dizer, do que seria a realidade em seu sentido mais essencial — não pode ser expresso senão por metáforas e analogias é sugerida por Platão no Fedro (1994). Há nesse diálogo passagens que defendem a idéia de que é impossível referir de forma literal à verdade última (247c). O próprio Sócrates se vale da alegoria do cocheiro e seus dois cavalos alados para dar conta da natureza da alma em sua relação com o cosmos (245c-248e). Também em outros diálogos como o Íon, Platão (1989) faz um elogio dos poetas enquanto seres inspirados de um "divino furor", que os permite ter acesso e transmitir conhecimentos que de outra forma permaneceriam velados (534). Quanto a Nietzsche, a referência de Delong é a uma passagem no final do capítulo 15 do Nascimento da tragédia. Nietzsche discorre então sobre o fato de que depois de avançado um determinado ponto na investigação de um tema, entra-se necessariamente em contato com regiões periféricas, em que a lógica que se seguia se inverte, enroscando-se sobre si mesma (NIETZSCHE, 1972, p. 97). Em outras obras como Da utilidade edesvanta- 
gem da história para a vida, Nietzsche vai exaltar, numa contraposição adicional, o poder plástico de determinadas estruturas estéticas, capazes de resgatar algo de a-histórico na história (NIETZSCHE, 1972, p. 246-250).

Embora sem considerar Platão ou Nietzsche, Hofstadter aborda as mesmas questões num sentido similar ao apontado por Delong. Também para Hofstadter, as reflexões mais audaciosas sobre os fundamentos de disciplinas cientificas como a lógica matemática e mesmo a física, teriam exposto limites intrínsecos do próprio ato de conhecer considerado na sua totalidade. A chave da questão seria uma diferença irredutível entre sujeito e objeto do conhecimento, que quando supostamente ultrapassada, necessariamente re-emergiria na figura de limites em relação a um meta-nível. Nesse sentido, Hofstadter considera o seguinte:

[...] é interessante notar que todos os resultados essencialmente dependentes da fusão entre sujeito e objeto têm sido resultados limitativos. Além dos teoremas limitativos [da metamatemática], há o princípio da incerteza de Heisenberg, segundo o qual a medida de uma quantidade torna impossível a medida simultânea de outra quantidade relacionada. Eu não sei por que todos esses resultados são limitativos. Sinta-se à vontade para dar uma resposta. (1979, p. 699) ${ }^{5}$.

Para Hofstadter, é um fato que avanços em áreas científicas mais tradicionais e rigorosas demonstraram esses limites. Mas ele deixa ao próprio leitor a liberdade para inferir conclusões mais gerais sobre esse fato.

O ponto aqui é o de que não seria possível elidir uma certa opacidade daquilo que se conhece. Quando se tenta tornar essa opacidade transparente, ela ressurge em alguma outra forma. Assim, a tentativa de construção de sistemas formais que garantiriam de antemão a resolução segura de problemas em qualqueráreada matemática, acabou por revelar as insuficiências paradoxais e irredutíveis dos próprios sistemas até então existentes. Em física, a tentativa de se encontrar num nível subatômico determinadas partículas mínimas cujo domínio garantiria o controle de objetos físicos em todas as escalas, acabou por revelaro caráter elusivo da realidade empíica exatamente no que pareceria ser esse nível mais fundamental.

Há entretanto outros elementos relacionados a essas questões que apontam numa direção muito diversa do que seria uma atitude meramente cética. É preciso entender que as implicações sugeridas pelos teoremas limitativos estão longe de solapar os resultados obtidos no âmbito das disciplinas em que eles ocorrem. Muito antes pelo contrario, eesse pontoéenfatizado tanto por Hofstadterquanto por Delong. Atinge-se aqui a raiz da crítica de Delong ao existencialismo, na medida em que esse movimento filosófico acabou de fato por se esgotar na defesa de um mero historicismo. E uma reconsideração dessa crítica não teria qualquer relevância para o presente se não fosse o fato de que - passada a moda existencialista — há uma série de outras posições filosóficas atuais passíveis do mesmo tipo de esvaziamento. A própria defesa dessas posições demandaria algo além da repetição ad infinitum de slogans legítimos na medida exata em que são triviais: a importância da diferença, da abertura ao devir, a relatividade da verdade etc.

Conforme frisa Hofstadter, sua posição nãoé a de que a verdade é simplesmente uma quimera. Trata-se antes do fato de que a obtenção de certas verdades é sempre uma tarefa em parte elusiva, não importa se perseguida por seres humanos isolados ou em conjunto (HOFSTADTER, 1979, p. 695). Especificamente com relação a verdades matemáticas, o próprio Gödel adotava a posição de um platonismo, ou realismo conceitual, criticando 
a noção de que tais verdades poderiam ser reduzidas a meras convenções sociais (1995, p. 295-300, $314,320)$. Mesmo que tais verdades não possam ser inteiramente estabelecidas, é possível apreendêlas através de um tipo de intuição familiar àqueles que com elas se defrontam (GÖDEL, 1995, p. 369373, 383-387). Permaneceria vigente uma noção de verdade enquanto meta-ideal quevaisemprealém do conjunto de coisas efetivamente enunciadas em uma dada teoria. Essa noção de verdade é elaboradaem termos formais pelo lógico polaco Alfred Tarski e tem sido associada aos teoremas limitativos (DELONG, 1970, p. 225,227; cf. KNEALE; KNEALE, 1962, p. 735-736).

Já se referiu acima ao curioso argumento de Delong, no qual ele alinha Platão e Nietzsche, recorrendo à noção de linguagem poética, para dar conta das implicações filosóficas mais gerais decorrentes dos teoremas limitativos. Na continuidade da mesma passagem, Delong afirma o seguinte:

[...] o que é característico de um discurso poético a respeito de um tema, é que explicações conflituosas e contraditórias são permissíveis. Enquanto eles são entendidos como literatura, não há necessidade de rejeitar o livro do Gênesis para se ler a llíada. (1970, p. 227)6.

A literatura se apresenta aqui não como oposta à verdade, mas como a área por excelência em que a verdade naquilo mesmo que ela nos escapa pode ser retomada. Do ponto de vista literário, há verdade tanto no Genesis quanto na llíada, por mais que tais textos divirjam. Esse ponto é extremamente interessante quando se considera que o maior risco de esvaziamento de certas filosofias atuais está em uma estetização generalizada da cultura, mas que subtrai do domínio estético qualquer comprometimento com noções mais substanciais, como verdade.

Seja em genealogias, desconstruções, ou outras análises contemporâneas em termos de diferença e devir, corre-se com freqüência o risco de uma forma mais fraca de estetização, que apenas contorna e até mesmo evade o caráter multideterminado, paradoxal e contraditório do que se queria examinar. A necessidade de fazer frentea esse tipo de esvaziamento é reconhecida por alguns autores que têm buscado explorar ao máximo o potencial de abordagens filosóficas contemporâneas mais contundentes. Christoph Menke ressalta o seguinte ponto em comum das considerações estéticas de Theodor Adorno e Jacques Derrida: “[...] multideterminação na experiência estética... emerge somente como o efeito da negação do entendimento experiencialmente desempenhada, aqual...é ela mesma fundada nesse exato conhecimento" (1998, p. 65)7. Querdizer, o caráter multideterminado, paradoxal, e mesmo contraditório de uma experiência estética legítima precisa estar colado ao objeto dessa experiênciae àquiloquedeleseconhece, mesmo quando se trata de negar ou ir além de tal conhecimento. Sendo assim, tambémemáreas nãocientíficas, estritamente falando, como a crítica literária, a investigação de um determinado objeto demanda a consideração de noções de ordem mais substancial como verdade e intuição, mesmo se essas são dilatadas num limite máximo.

Um exemplo concreto é útil aqui. Comentários a Marcel Proust se encontram espalhados ao longo de várias obras de Adorno. Em Notas sobre Literatura, Adorno estabelece um paralelo entre Prouste Henri Bergson, apontando para a alergia de ambos autores ao pensamento pré-confeccionado. A idéia depensamento pré-confeccionado vem de umaanalogia do próprio Bergson, que compara o uso superficial e mecânico de conceitos a roupas que se compram prontas e caem de forma relaxada sobre o corpo, porque não são feitas sob medida (ADORNO, 1961, p. 96-97). Há algo de esdrúxulo nessa analogia, porque ela alinha experiências provindas de esferasque tradicionalmente separamos: filosofia ealtacostura. Ocorreque justamente oque Adorno admira em Prousté a capacidade de conferir seriedade (filo- 
sófica!) a detalhes que normalmente se tem por fúteis. Proust se dedica a acompanhar a duração específica de momentos isolados, resgatando no cotidiano as experiências mais singulares. Dessa forma, ele cria constelações de necessidade em coisas inteiramente contingentes (ADORNO, 1961, p. 105): umvestido deOdete Swan, ocheiro de umidade num lavatório público do Champs-Elysées (PROUST, 1919, p. 90-91). Enadadissoémeramentealeatório. A escrita de Proust se constrói por uma análise de fragmentos de uma memória intensiva das coisas, que ele busca obsessivamente. Quando, para dar conta dessa escrita, o crítico é obrigado a se valer de umaanalogia esdrúxula, ele estáigualmente seguindo de forma minimamente racional uma intuição que possui a respeito do valor da obra do escritor, que ele visa de uma forma ou outra evidenciar. Há um compromisso tanto com a própria intuição, quanto coma obra, o trabalho autor, etambém o que se pode denominar, em termos tradicionais, verdade. Nesse sentido, dizer que o pensamento rigoroso deve ser como uma forma de alta-costura está longe de ser umabanalização ou mero esvaziamento de qualquer uma dessas atividades. Com audácia similar, já se disse hámuito tempo, muitoantes de Proustou Gödel que "todo o acaso" deveria ser "banido" da obra poética moderna, a qual se caracterizaria por um "olhar lúcido", sendo uma forma de "escrutínio" matemático sobre umbaterdeasas devorador (Charles Baudelaire sobreEdgar Allan Poe, conformereferidoemDELFEL, 1951,p. 23).

Notas

${ }^{1}$ To my knowledge, no tone of the leading existentialists - Heidegger, Sartre, Jaspers, Merleau-Ponty - has even mentioned the limitative theorems [of metamathematics]. The existentialists disagree among themselves about many things, but they would all agree in not assigning a technical subject such as mathematical logic a high place let alone a central one - in their theory of knowledge. Yet they wish to talk about proof or truth or the limitations of man.

2 [...] what counts as arithmetic truth is dependent on what people decide is arithmetically true... Just as there can be no complete systematic abstract account of why we speak English the way we do, so here can be no complete account as to why we accept one rather than another statement as arithmetically true.

${ }^{3}[. .$.$] it is as if somebody had known musical scores all his life, but purely visually - and then, all of a sudden,$ someone introduced him to the mapping between sounds and musical scores. What a rich, new world!

${ }^{4}$ Uma discussão interessante da relação entre Nietzsche e Platão, a qual daria um pouco mais de embasamento a esse alinhamento proposto por Delong, pode ser encontrada em Giacoia Júnior (1997).

${ }^{5}[\ldots]$ it is interesting to note that all results essentially dependent on the fusion of subject and object have been limitative results. In addition to the limitative theorems [of metamathematics], there is Heisenberg's uncertainty 
principle, which says that measuring one quantity renders impossible the simultaneous measurement of a related quantity. I don't know why all these results are limitative. Make of it what you will.

${ }^{6}[. .$.$] what is characteristic of poetic discourse about something is that conflicting and contradiction accounts about$ it are permissible. If one understands them as literature there is no need to reject the book of Genesis in order to read the Iliad.

${ }^{7}[. .$.$] multideterminacy in aesthetic experience... arises only as the effect of the experientially enacted negation of$ understanding, which... is itself grounded in this very understanding.

\section{Referências}

ADORNO, T. W. Noten zur Literatur II. Frankfurt: Suhrkamp Verlag, 1961.

DAWSON, J. W. J. Logical dilemmas. The life and work of Kurt Gödel. Wellesley: A. K. Peters, 1997.

DELFEL, G. L'esthétique de Stéphane Mallarmé. Paris: Flammarion, 1951.

DELONG, H. A profile of mathematical logic. Massachusetts: Addison-Wesley, 1970.

GIACOIA JÚNIOR, O. O Platão de Nietzsche. O Nietzsche de Platão. Cadernos Nietzsche, São Paulo, n. 3, p. 23-36, 1997.

GÖDEL, K. Collected Works: unpublished essays and lectures, 3. Oxford: Oxford University Press, 1995.

HOFSTADTER, D. R. Gödel, Escher, Bach: an eternal golden brad. New York: Basic Books, 1979.

HOFSTADTER, D. R. Metamagical themas: questing for the essence of mind and pattern. New York: Basic Books, 1985.

KNEALE, W.; KNEALE, M. The development of logic. Oxford: Clarendon Press, 1962.

MENKE, C. The sovereignty of art: aesthetic negativity in Adorno and Derrida. Cambridge: MIT Press, 1998.

NIETZSCHE, F. Die Geburt der Tragödie. Unzeitgemäß Betrachtungen I-III. Werke. Dritte Abteilung. Erster Band. Berlin: Walter de Gruyer, 1972.

PENROSE, R. The Emperor's New Mind. Concerning computers, minds, and the laws of Physics. Oxford: Oxford University Press, 1989.

PLATÃO. Oeuvres Complètes. Ion - Ménexène - Euthydème. Texte Établi et Traduit par Louis Méridier. Paris: Les Belles Lettres, 1989. v. 5, $1^{\text {er }}$ Partie.

PLATÃO. Oeuvres Complètes. Phèdre. Texte Établi par Claudio Moreschini et Traduit par Paul Vicaire. Paris: Les Belles Lettres, 1994. v. 4, $3^{\text {e }}$ Partie.

PROUST, M. A I'Ombre des Jeunes Filles en Fleurs. Paris: Gallimard, 1919. 3 v.

Recebido em agosto de 2007

Aceito para publicação em outubro de 2007

\section{Alessandro Zir}

Doutorando Dalhousie University.

Philosophy and History of Science.

azir@DAL.CA 